\title{
Optimal control of irrupting pest populations in a climate-driven ecosystem
}

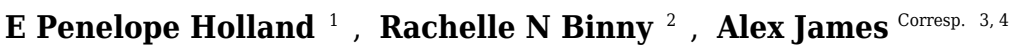 \\ 1 Department of Biology, University of York, York, United Kingdom \\ 2 Manaaki Whenua Landcare Research, Lincoln, New Zealand \\ 3 Biomathematics Research Centre, University of Canterbury, Christchurch, New Zealand \\ 4 Te Pūnaha Matatini, New Zealand \\ Corresponding Author: Alex James \\ Email address: alex.james@canterbury.ac.nz
}

Irruptions of small consumer populations, driven by pulsed resources, can lead to adverse effects including the decline of indigenous species or increased disease spread. Broadscale pest management to combat such effects benefits from forecasting of irruptions and an assessment of the optimal control conditions for minimising consumer abundance. We use a climate-based consumer-resource model to predict irruptions of a pest species (Mus musculus) population in response to masting (episodic synchronous seed production) and extend this model to account for broad-scale pest control of mice using toxic bait. The extended model is used to forecast the magnitude and frequency of pest irruptions under low, moderate and high control levels, and for different timings of control operations. In particular, we assess the optimal control timing required to minimise the frequency with which pests reach 'plague' levels, whilst avoiding excessive toxin use. Model predictions suggest the optimal timing for mouse control in beech forest, with respect to minimising plague time, is mid-September. Of the control regimes considered, a seedfall driven biannual-biennial regime gave the greatest reduction in plague time and plague years for low and moderate control levels. Although inspired by a model validated using house mouse populations in New Zealand forests, our modelling approach is easily adapted for application to other climate-driven systems where broad-scale control is conducted on irrupting pest populations. 


\section{Optimal control of irrupting pest populations in a climate-driven ecosystem}

2 E Penelope Holland ${ }^{1}$, Rachelle N Binny ${ }^{2,3}$ and Alex James ${ }^{3,4^{*}}$

$3{ }^{1}$ Department of Biology, University of York, York, United Kingdom.

$4 \quad{ }^{2}$ Manaaki Whenua Landcare Research, Lincoln, New Zealand.

$5 \quad{ }^{3}$ Te Pūnaha Matatini, New Zealand.

$6{ }^{4}$ Biomathematics Research Centre, University of Canterbury, Christchurch, New Zealand.

$7 \quad *$ Correspondence author. Email:alex.james@canterbury.ac.nz

\section{Abstract}

Irruptions of small consumer populations, driven by pulsed resources, can lead to adverse effects including the decline of indigenous species or increased disease spread. Broad-scale pest management to combat such effects benefits from forecasting of irruptions and an assessment of the optimal control conditions for minimising consumer abundance. We use a climate-based consumer-resource model to predict irruptions of a pest species (Mus musculus) population in response to masting (episodic synchronous seed production) and extend this model to account for broad-scale pest control of mice using toxic bait. The extended model is used to forecast the magnitude and frequency of pest irruptions under low, moderate and high control levels, and for different timings of control operations. In particular, we assess the optimal control timing required to minimise the frequency with which pests reach 'plague' levels, whilst avoiding excessive toxin use. Model predictions suggest the optimal timing for mouse control in beech forest, with respect to minimising plague time, is mid-September. Of the control regimes considered, a seedfall driven biannual-biennial regime gave the greatest reduction in plague time and plague years for low and moderate control levels. Although inspired by a model validated 
using house mouse populations in New Zealand forests, our modelling approach is easily adapted for application to other climate-driven systems where broad-scale control is conducted on irrupting pest populations.

\section{Introduction}

Pulses in food resources can drive irruptions of small consumers and trigger cascading responses in population dynamics across multiple trophic levels (Ostfeld \& Keesing, 2000). This can result in the decline or extinction of indigenous species (Innes et al., 2010) and/or an increase in disease spread (Jones et al., 1998), particularly in ecosystems inhabited by pest species. To avoid or mitigate the impact of pest populations on the ecological community, it is necessary to forecast irruptions, often using weather-based forecast models (e.g. Kelly et al., 2013; Magarey \& Isard, 2017), and then optimise the timing and intensity of management operations to reduce pest abundance at critical times of the year (e.g. Singleton et al., 2007).

The diverse effects of mast seeding - the synchronous intermittent production of large seed crops (Allen et al., 2012; Kelly \& Sork, 2002) - on ecological communities around the world are illustrated well using rodent populations in forests. Yellow-necked mice (Apodemus flavicollis) have increased winter survival and rapid population growth following mast seeding in oak (Quercus robur) and hornbeam (Carpinus betulus) in Biolowieza Primeval Forest in Poland, with a corresponding increase and peak in predator populations such as the pine marten (Martes martes) a few months to a year later (Ostfeld \& Keesing, 2000; Pucek et al., 1993). When rodent prey becomes scarce following an irruption, pine martens compensate by increasing consumption of alternative resources including birds and berries (Jedrzejewska \& Jedrzejewski, 1998). Forest bird populations are also limited by predation by raptors, e.g. buzzards, which undergo prey-switching from rodents to birds following a crash in rodent abundance (Jedrzejewska 
47 \& Jedrzejewski, 1998). In oak (Quercus spp.) forest in the eastern U.S., white-footed mice (Peromyscus

48 leucopus) respond similarly to acorn masts, with increased winter survival and breeding success (Jones et

49 al., 1998). However, in this case mice are also predators, playing an important role in suppressing gypsy moth (Lymantria dispar), an invasive and outbreaking species. Defoliation by gypsy moths can delay and reduce mast production, creating a negative feedback loop for the mast-driven mouse populations with catastrophic consequences for tree growth and survival as well as reduced mouse abundance (Jones et al., 1998). However, high densities of mice lead to increases in tick (Ixodes scapularis) populations, and the associated spread of Lyme disease in humans (Jones et al., 1998).

In South America, rodent outbreaks are associated with emerging viral diseases such as hantavirus (Jaksic \& Lima, 2003). These outbreaks occur after bamboo (Chusquea sp. and Merostachys sp.) masts, but may also follow heavy rainfall events (Jaksic \& Lima, 2003), emphasizing the need for ecologically sound pest forecasting models. Introduced bamboo (Melocanna baccifera) is a well-used non-timber forest product in India, but rodent (Rattus sp. and Mus sp.) migration towards agricultural areas following mast events can have devastating effects on standing crops and stored grains, as well as increasing the risk of infection for rodent-borne diseases (Biswas et al., 2016). It has also been suggested that masting by introduced Asian bamboos into North America, particularly the Pacific Northwest, poses a health risk to humans as a result of population irruptions and subsequent dispersal of deer mice (Peromyscus maniculatus, a hantavirus carrier) following mast seed depletion (Smith et al., 2015). through the application of baits laced with rodenticide toxin, applied either via aerial drops or groundbased bait stations (Singleton et al., 2010). In Australia, for example, plaguing mouse populations can exceed densities of 1000 mice per hectare, causing significant damage to cereal crops (Singleton et al., 2001). Sterilised wheat grains coated with zinc phosphide toxin are applied in and around crops, aerially 
70

71

72

73

74

75

or using calibrated fertiliser spreaders, and can reduce the mouse population by $40-98 \%$ (Mutze \& Sinclair, 2004).

In New Zealand, invasive house mouse (Mus musculus) populations undergo episodic outbreaks in response to high seedfall, particularly in the heavy masts of native beech forest (Nothofagus species) (Fitzgerald et al., 1996; King, 1983; Ruscoe, 2001) or rimu (Dacrydium cupressinum) (Ruscoe et al., 2004). Irruptions in beech forest occur predominantly in late summer to autumn (i.e. February-May) (Ruscoe et al., 2003; Wardle, 1984) and are accompanied by an increase in abundance of other seed consumers, including ship rats (Rattus rattus) (Studholme, 2000) and kiore (R. exulans) (Ruscoe \& Pech, 2010). Small mammal predators, predominantly invasive stoats (Mustela erminea), benefit from the irruptions of prey and increase after a delay caused by seasonal breeding (King, 1983). These dynamics are harmful to a wide range of native fauna. For instance, in addition to fallen seed, mouse and rat diets comprise invertebrates (Fitzgerald et al., 1996; Jones \& Toft, 2006; Miller \& Miller, 1995; Ruscoe \& Murphy, 2005), bird chicks and eggs (O'Donnell \& Phillipson, 1996; Wilson et al., 2006; Wilson et al., 1998), and lizards (Norbury et al., 2014). Stoats also have a flexible diet, and in masting forests will switch from mice as their primary food source, to predating on birds and invertebrates when mice become scarce (Murphy et al., 2016; Wilson et al., 1998).

Despite the threat posed to native biota, there is currently no broad-scale control targeting mice alone in mainland New Zealand. This is primarily due to higher prioritisation of control for other small mammal pest targets, e.g. common brushtail possum (Trichosurus vulpecula), rats (Rattus sp.) and mustelids (Mustela sp.), which are considered to pose a greater risk to native flora and fauna (Innes et al., 2010; Ruscoe \& Pech, 2010). In addition, the lack of cost-effective mouse-specific control tools and public concern around widespread toxin use, means that the broad-scale management of mice on mainland New Zealand still presents a major challenge (Ruscoe \& Pech, 2010). Ground-based control (e.g. trapping) 
93 targeting mice alone has been undertaken on smaller spatial scales within predator-fenced sanctuaries,

94 where all other vertebrate pests have been eradicated, and has been shown to confer benefits to 95 biodiversity (Watts et al., 2017). Broad-scale multi-species control operations involving aerially applied bait laced within sodium fluoroacetate (1080) toxin are undertaken in New Zealand to control rodents, possums and stoats (via secondary poisoning when stoats consume poisoned rodents (Murphy et al., 1999)). These operations have been partially successful in reducing mouse abundance but less so than for other small mammals (Elliott \& Kemp, 2016), likely due to lower uptake of the 1080 bait by mice compared to other targets (Fisher \& Airey, 2009; O'Connor et al., 2005). There has been some success with mouse eradication programmes on New Zealand's offshore islands, predominantly through aerial application of the second-generation anti-coagulant toxin brodifacoum (Mackay et al., 2007). However, long-term broad-scale brodifacoum use is avoided on mainland New Zealand due to its persistence in the environment and risks to non-target species (Eason et al., 2002).

Control targeting only a subset of predators in an ecosystem may lead to an increase in abundance of other smaller predators, an effect termed 'mesopredator release', causing a subsequent decline in release of mouse populations has been observed both on islands (Simberloff, 2002) and on the mainland (Norbury et al., 2013). It is therefore becoming increasingly important to have the understanding and technologies in place to effectively forecast and manage irrupting mouse populations over large spatial scales. In particular, the optimal timing for broad-scale mouse control on mainland New Zealand remains

112 a critical knowledge gap. For eradication of mice on islands, the preferred season for control is winter to early spring when food is likely to be limiting because this maximizes bait up-take (Broome et al., 2017).

114 The optimal timing for broad-scale aerial 1080 control targeting irrupting rodents and stoats is between 115 July and November in a mast year, determined with the aim of minimising rat abundance. However, 116 operational logistics (e.g. availability of helicopters), weather and legal requirements also place significant 
117 constraints on timing (Elliott \& Kemp, 2016). Innes et al. (1995) proposed that broad-scale aerial

118 operations targeting ship rats (Rattus rattus) to protect nesting birds should coincide with the onset of

119 nesting each year. The conceptual model of Wilson et al. (1998) for mouse dynamics in beech forest

120 suggests conducting control in November prior to a mast would have little effect, while the November

121 after a mast would be too late (see e.g. Fig. 5 in Wilson et al. (1998)). However, conducting control in

122 February at the start of a mast and/or May during heavy seedfall may be optimal.

123 Models for irrupting mouse populations require good predictions of the size and timing of masts.

124 Temperature and rainfall in the years before the mast event are almost always the primary cue for mast

125 seeding (Janzen, 1971). Kelly et al. (2013) proposed a generic and widely applicable model using the

126 change in temperature in a set period over the previous two years $(\Delta \mathrm{T})$ as the sole predictor. This model

127 offered much improved predictions over other simple models and has been shown to be applicable to a

128 wide range of plant species around the world, including oak and many New Zealand species, either as a

129 cue or a proximate driver of masting (Kelly et al., 2013; Pearse et al., 2014).

130 Holland et al. (2015) previously developed a climate-based consumer-resource model for mouse

131 irruptions in masting forests, parameterised using long-term temperature, hard beech (Fuscospora

132 truncata) seedfall and house mouse (Mus musculus) abundance data from mixed beech-podocarp-

133 broadleaved forest in Orongorongo Valley (OV), New Zealand. Seedfall was predicted using the $\Delta T$ model

134 (Kelly et al., 2013). In this paper, we extend the Holland et al. (2015) model of mouse population dynamics

135 driven by pulses in food resource, to account for broad-scale mouse control. We use the extended model

136 to forecast population irruptions (timing and size) and the impact of pest control on mouse populations,

137 to assess if and how we can avoid 'plague' levels of mice while also avoiding excessive poison use.

138 Predictions of the impacts of tailored vs. untailored vs. no control will be crucial for effective and efficient

139 broad-scale management of irrupting mouse populations. 


\section{Consumer-resource model}

142 The underlying consumer-resource model is the best-fit model developed by Holland et al. (2015). Relative

143 mouse abundance $M(t)$ is quantified by an index: captures per 100 trap nights (C/100TN) (Ruscoe et al.,

144 2001). The rate of change of $M$ over time $t$ (years) is given by

$145 \frac{d M}{d t}=\left(\alpha g(F)-\mu_{1}-\mu_{2} M-B(t)\right) M$ eqn 1

146 Food availability $F$ (seeds $\mathrm{m}^{-2}$ ) is predicted by the functional response $g(F)$ and $\alpha$ is the demographic

147 efficiency of mice (i.e. efficiency at converting food into recruitment for the mouse population). The total

148 mortality rate is $\mu_{1}-\mu_{2} M-B(t)$, where the parameters $\mu_{1}$ and $\mu_{2}$ are density-independent and density-

149 dependent mortality rates respectively. They may both be positive or negative depending on non-food 150 related processes, e.g. predation, social interactions, Allee effects. In this paper, we extend the previously

151 published model by adding $B(t)$, which is a time-dependent, density-independent rate of mortality due 152 to control by bait application (see below).

153 The original model tested four candidate models for the food availability functional response. The best fit 154 was a Holling II (Ivlev) function where $c$ (seeds $\mathrm{m}^{-2}$ mouse ${ }^{-1}$ year $^{-1}$ ) is the maximum per capita feeding rate 155 and $e\left(\left(\text { seeds } \mathrm{m}^{-2}\right)^{-1}\right)$ is a measure of foraging efficiency:

$156 g(F)=c(1-\exp (-e F))$ eqn 2

157 The rate of change of available food over time is modelled by

$158 \frac{d F}{d t}=S(t)-h F-g(F) M$, eqn 3 
159 where the second term, $h F$, describes the change in available food that happens throughout the year at

160 a constant rate $h\left(\right.$ year $^{-1}$ ) unrelated to mouse density and the third term, $g(F) M$, describes the rate of 161 seed consumption by mice. The first term, $S(t)$, describes the rate at which food is delivered as a function 162 of time, with

$163 S(t)=\left\{\begin{array}{c}\frac{F_{y}}{0.25} \text { if } 0 \leq t-\text { floor }(t)<0.25 \\ 0 \text { otherwise. }\end{array}\right.$ eqn 4

164 The floor function rounds $t$ down to the largest integer smaller than $t$. Thus, during the $y^{\text {th }}$ annual cycle, a 165 total amount of seed $F_{y}$ is produced, which is delivered at a constant rate over the first quarter of the year 166 (nominally February - April). At the start of each year we set $F(t)=0$, i.e. seed is not carried over between 167 years. The annual seedfall amount $F_{y}$, was determined by a climate induced seedfall model (see below). 168 All parameter values are given in Table 1 and were those determined as best-fit parameter values by Holland et al. (2015) (Table 2 in Holland et al. (2015)). These were chosen by modelling mouse density over 25 years using observed annual seedfall data from the OV (starting February 1972) as the annual values of seed $F_{y}$. Mouse density at the start of each quarter was extracted from the continuous-time model prediction. These predicted values were compared to observed quarterly mouse density data from the OV collected over the same time period (quarterly, February 1972 - November 1996) and best-fit parameter estimates chosen by minimising the root mean square error. Holland et al. (2015) showed that with these best-fit parameter values the model predicted all major outbreaks in mouse density occurring in the 25 year observed mouse density (C/100TN) time series, although it tended to slightly under-predict 177 the magnitude of outbreaks. describes the time since the $i^{\text {th }}$ bait application. After application, bait degrades according to a simple 
181 availability, i.e. at the time of application $\left(t-t_{i}^{*}=0\right)$. Therefore, bait availability $b_{i}(t)$ from the $i^{\text {th }}$

182 application is described by a piecewise function

$183 b_{i}(t)=\left\{\begin{array}{cl}B_{0} \exp \left(-d\left(t-t_{i}^{*}\right)\right), & \text { if } t_{i}^{*} \leq t<t_{i+1}^{*} \\ 0, & \text { otherwise, }\end{array}\right.$ eqn 5

184 and overall bait availability $B(t)$ at time $t$ is given by

$185 B(t)=\sum_{i=1}^{n-1} b_{i}(t)$,

eqn 6

186 for $n$ bait applications. In the absence of mice, bait is considered to be inactive after one month, so we

187 choose $d=50$ (meaning that $b_{i}(t)$ has decayed to $<2 \%$ of its original size one month after the $i^{\text {th }}$

188 application, and $<0.02 \%$ of its original size after two months. It is presumed that, compared to this decay

189 rate, the effect of mouse predation on bait levels is negligible. Note that the actual value of $B_{0}$ is defined

190 later in terms of the kill success rate.

191 Climate-induced seedfall model

192 A 1000 year normally distributed temperature time series $T_{1}, T_{2}, \ldots T_{1000}$, was generated where

$193 T_{y} \sim N(14,1)$.

eqn 6

194 This represents historical mean summer temperatures (daily average for the three month period

195 January to March) in the Orongorongo Valley (hereafter OV), 1972-2014. Randomly generating time-

196 series for the OV in this way was shown to be a valid approach by Holland and James (2015). From this, a

197 time series was calculated using the $\Delta$ T model of Kelly et al. (2013), where

$198 \Delta T_{y}=T_{y}-T_{y-1}$.

eqn 7 
199 Annual seedfall predictions were made using the following linear relationship fitted to observed OV

200 beech seedfall data (1972-1996) by Holland et al. (2015):

$201 \log _{10} F_{y}=0.33+0.97 \Delta T_{y}+\epsilon_{y}$. eqn 8

202 The noise term was chosen to have distribution $\epsilon_{y} \sim N(0,1.3)$ to give a correlation between change in

203 temperature and seedfall of $r^{2} \approx 0.54$ corresponding to the findings of Kelly et al. (2013). These seedfall 204 time series were used as annual inputs of $F_{y}$ to the mouse model above. Mouse density (C/100TN) was 205 simulated for each of the control scenarios above, with $M(0)=1.0$.

\section{Plague definitions}

207 We define the mouse density plague level, $M_{p}=2.02$, to be the maximum mouse density in a median seedfall year if the initial mouse density is one, i.e. $M(0)=1$, (see Figure 1). Using this definition, if the mouse density was 1 at the start of the year $(M(0)=1) 50 \%$ of years would be defined as plague years i.e. the mouse density 'just' reached plague level at some point during the year. In a longer time series where no control measures are applied (Figure 2) and the density is continuous across years, i.e. mouse density at the start of the year is the density at the end of the previous year, the plague level definition is not changed and the proportion of years that are plague years is much higher, $85 \%$. Specific thresholds

for what constitutes a mouse 'plague' or eruption in New Zealand have not been formally defined in the literature; it is difficult to measure exact population densities, and it is not known exactly at what threshold level mice may have an impact on native biodiversity. We therefore use the term 'plague', to mean greater than average population abundance for an extended period of time, i.e. demonstrably not an undetectable population and therefore likely to have some impact, and a convenient reference point with which to compare scenarios. In the 25 year time-series of observed mouse abundance from the OV, 
221 eruptions. In addition, mouse abundance was above the 2.02 level in $80 \%$ of years, suggesting that our

222 definition for plague level and estimate of proportion of plague years are reasonable in this context. We

223 also define plague time, the proportion of time during which the mouse density is above the plague level.

224 For example, in Figure 1 the plague time for the mast year trajectory is 0.89 . In the long term time series

225 of Figure 2 the plague time is 0.71 . Finally we define the plague size, the highest mouse density during the

226 plague period. In the Figure 1 example, the plague size for the mast trajectory is 6.93 . In the long term

227 series (Figure 2), the expected plague size, given that a plague occurs, is 5.7. Higher values of $M_{p}$ could be

228 used with the same plague definitions given here, with qualitatively similar results.

\section{Control definitions}

The strength of the control impulse is governed by the parameter $B_{0}$, which is the value of $B(t)$ at the time of bait application $t=t_{i}^{*}$ (eqns 5-6). The absolute value of the control impulse is of little practical use in modelling terms, though operationally it relates to control effort and a parameter value could be calibrated for a given operation. A more appropriate measure of control size is the control success, typically assessed in terms of percentage kill, defined here as the relative decrease in the mouse density one month after the control impulse. The control success will change depending on the current mast level and mouse density but percentage kill is still a useful and widely used measure (Elliott \& Kemp, 2016; Innes et al., 1995). In the example of Figure 1 (black dotted line), where $B_{0}=150$ and control is applied at the start of the mast season, control success is $88 \%$. Even with this relatively high level of control (consistent with historic broad-scale aerial poison operations for rodents (Innes et al., 1995)), the mouse density at the end of the year remains high as the population recovers, and the mouse density rises above

241 the plague level during September. However, both the plague time (0.31) and the plague size (2.18) are

242 much lower than in the uncontrolled mast year. Crucially, for the success of native species that rely on 
243 beech mast for food, the seedfall level is much higher in the controlled scenario compared to the 244 uncontrolled.

\section{Scenarios}

246 To obtain precise estimates for expected plague time, plague size and proportion of plague years under

247 different control scenarios, we ran the extended model (eqns 1-6) for a 1000 year long simulation with

$248 M(0)=1$, using a seedfall time series generated with eqns 8-9 from a temperature time series generated 249 using eqn 7. In this longer simulation, the initial mouse density is not reset to 1 each year but continues 250 with the value at the end of the previous year. Seedfall is reset to zero at the beginning of each year to 251 reflect the inedibility of the previous year's seed. Note that all the control scenarios used the same 252 underlying seedfall series.

\section{Optimal control timing}

254 Initially, we assume that control can only be applied once each year and we examine three levels of 255 control: low, medium and high, $B_{0}=50,100,150$, respectively. For each level of control, we used the 2561000 year weather/seedfall time series, applying control at a range of times throughout the year. We 257 calculated the proportion of plague years, proportion of time above plague level (i.e. plague time), and 258 average plague size for each control application time.

Tailored control

We now consider how other control options with similar costs could offer greater benefit if tailored. An alternative to annual control could be a biannual-biennial regime, i.e. control is applied twice a year every two years. In some cases this may be more cost effective as resources only need to be acquired every other year; it may also be socially advantageous if the application of poison is somewhat controversial and its use needs to be limited. As operational costs may be considerable (particularly labour and 
265

266

267

268

\section{Results}

When mice are not controlled, $85 \%$ of years are plague years, the mouse density is above the plague level for $71 \%$ of the time and the average plague size is 5.71 (see Figure 2 for a 20 year time series example).

transport/flight-time), and the amount of bait applied contributes relatively little to the overall cost of each control dose, we do not consider control via very frequent smaller doses here. We used the 1000 year seedfall simulation to compare three biannual-biennial regimes with no control and the annual control regime described above:

1. Regular biennial control: Control occurs every second year and is executed in early September and a month later in early October, i.e. straddling the optimal control period (see Results).

2. Seedfall determined control: Control occurs in years when seedfall is above the median (i.e. with the same long term average frequency as regular biennial control), in early September and early October.

3. Climate determined control: Control occurs in years when the seedfall temperature driver $\Delta T$ is above the median (i.e. with the same long term average frequency as regular biennial control but with more opportunity for error in true/false seedfall prediction), in early September and early October.

Regime two could be used if the seedfall could be measured early enough to plan a control application that year. In cases where this was too late to muster a control application then regime three may be of use.

\section{Optimal control timing}


286 As the control time is changed across the year the plague time varies (Figure 3A). The different control

287 levels (low, medium and high) have a much stronger effect on the plague time than the control timing.

288 For example, under the low control regime, where the control success rate is between 50 and $60 \%$, the optimal control timing to reduce plague time is spring (mid-September) before the mast season starts when plague time is 0.36 . Conversely the lowest reduction is seen in autumn (late April) at the end of the mast season which reduces the plague time to 0.42 . The optimal control time at medium and high control levels is also around mid-September. Medium control, which has an $80-85 \%$ success rate, reduces the plague time to 0.20 , while high control has a $92-94 \%$ success rate and reduces the plague time to 0.045 .

In contrast, the expected plague size (Figure 3B) appears to be strongly affected by control timing, in particular for low and medium control levels. The optimal timing to reduce plague time gives the least reduction in expected plague size. Initially this seems counter-intuitive but less so after recalling the definition of expected plague size (the maximum mouse density given that there is a plague). On examination of the time series (Figure 4) for control during the mast season (March - A, C, E) and after (September - B, D, F) we see that the small reduction in plague time between the control timings comes from the years where the plague threshold is only just exceeded. For low control effort both timings have relatively little impact on the maximum mouse density reached for large plagues, but in post mast control (September) the timing is appropriate to reduce mouse density to below the plague threshold for smaller control is during the mast the small plagues still occur. Larger plagues still occur and reach similar maximum densities as in the absence of control for both timings. When calculating an expected plague size over the entire time-series, smaller plagues will reduce the average. Therefore, while the larger 
expected density over the entire time-series, loses this subtlety and gives results similar to the plague

310 time metric.

\section{Tailored control}

312 Seedfall- and climate-determined biennial-biannual control regimes are more effective in reducing

313 proportion of plague years and time above plague levels than a regular biennial-biannual control regime

314 (Table 2). For both the low and medium control levels a seedfall driven biennial-biannual control regime

315 is more effective than annual control (Table 2). If the control trigger is based on climatic variables rather

316 than actual seedfall, the biennial-biannual regime is slightly less effective than annual control, though the

317 differences in plague time between these methods is relatively small.

\section{Discussion}

Management to mitigate the adverse effects of irrupting small consumers should be optimised to ensure

that the limited resources available to managers are implemented to have the greatest impact and to meet control objectives. In this work, we offer insights into the dynamics of an irrupting rodent population undergoing broad-scale aerial control in an ecosystem with pulsed resources. It is clear from our results that the timing and frequency of control can affect the time spent above the plague threshold. While we

have focused on mouse irruptions in beech forest, insights from this work have clear ramifications for dynamics of predators, prey and disease spread in other systems with climate-driven pulsed resources and outbreaking consumers worldwide.

There is currently no broad-scale control of mice alone in mainland New Zealand, due, in part, to the higher prioritisation of other vertebrate pest targets. In addition, achieving a large reduction in mouse abundance at large spatial scale is difficult with the control tools currently available on the mainland 330 (Ruscoe \& Pech, 2010). As a result, considerably less is known about the optimal control practices when 
331 targeting mice, compared to other small mammals. In a year of high seedfall and in the absence of control,

332 our model predicts that mouse populations exceed the plague threshold and drive a rapid decline in the

333 amount of available seed. As seedfall is depleted, mouse density decreases but still remains above the

334 plague threshold by the end of the mast year. As well as the local impacts of this prolonged high mouse

335 density, there is a risk that after seedfall depletion mice may disperse out of beech forest into other

336 adjacent areas or habitats (Choquenot \& Ruscoe, 2000; Ostfeld \& Keesing, 2000). Dispersal of outbreaking

337 rodents has been reported globally and contributes to disease spread (Deter et al., 2008; Smith et al.,

338 2015), damage to agriculture (Biswas et al., 2016; Newsome, 1969; Ruscoe, 1996) or declines in

339 indigenous biota (Smith et al., 2016). However, conducting high level mouse control in mast years can

340 successfully reduce mouse density to below plague level and to an extent where seed abundance is closer

341 to that observed in the absence of mice. This should provide more food resource for other indigenous

342 consumers competing for seedfall, and reduce the risks of dispersal and predation by mice and stoats.

343 Our model quantifies relative mouse abundance as an index of captures per 100 trap nights. Measuring

344 actual mouse density in the field is difficult and costly, therefore indices such as $\mathrm{C} / 100 \mathrm{TN}$ or a rodent

345 tracking index (i.e. mean percentage of 'run-through' tracking tunnels containing mouse prints per line)

346 are commonly used (Blackwell et al., 2002; Ruscoe et al., 2001). Quantifying relative abundance in this

347 way facilitates model parameterisation and validation of model predictions using observation data that is

348 more readily available to managers. Our model assumes logistic-type density dependence in the mouse

349 population, which has been shown to be a good description of density-dependent dynamics in small

350 rodent populations (see e.g. Turchin and Ostfeld (1997)). The best-fit parameters were similar to those

351 used in other models of house mouse population dynamics, for example the model of Choquenot and

352 Ruscoe (2000) also had a positive density-independent growth term and a negative density-dependent 353 growth term. 
354 The three values chosen for peak bait availability to model low, moderate and high control levels, gave

355 control success rates (measured as percentage kill) in the ranges $50-60 \%, 80-85 \%$ and $92-94 \%$,

356 respectively. How these ranges relate to success for real control operations, that aim to suppress as

357 opposed to eradicate mouse populations, will depend on control objectives. To date, very little has been

358 published on the density-impact relationships for mouse abundance and biodiversity in New Zealand.

359 These knowledge deficits currently present a major barrier for managers, both in terms of setting

360 conservation aims and measuring success of mouse control operations. However, our modelling

361 framework provides predictions of mouse abundance and kill rates that can be readily applied to real

362 control operations, as research advances in this area and new thresholds for successful suppression of

363 mouse populations on mainland New Zealand are set.

364 Our model predicts that the optimal timing for mouse control in beech forest, with respect to minimising plague time, is mid-September. This timing fits within the recommended range for broad-scale aerial 1080 control targeting rats and stoats (Elliott \& Kemp, 2016). Across all the regimes considered here, the seedfall driven biannual-biennial regime gave the greatest reduction in plague time and plague years for low and moderate control levels, although the differences between regimes were relatively small. Managers will need to take additional factors into consideration when selecting an optimal approach, for instance the benefits of seedfall driven control need to be weighed against the cost and effort associated

372 is readily available.

374 a case study of optimal control for mouse populations in New Zealand hard beech forest, where the aim 375 is to minimise plague time. Different compositions of masting species in other forests will drive slightly 376 different seedfall and mouse dynamics. For example, Ruscoe et al. (2004) reported a later onset of mouse 
377 population increase due to heavy rimu (D. cupressium) masting occurring two to three months later than

378 in beech forest. Therefore, optimal control conditions will likely differ for other forest compositions.

379 Nonetheless, our model and approach could be easily adapted for application to other habitats with

380 climate-driven pulsed resources, for which temperature, resource, and consumer abundance data is

381 available for parameterisation. Similarly, it would be straightforward to alter our model to account for

382 additional drivers of population irruptions, such as the effect of rainfall alongside bamboo masts on rodent

383 outbreaks in South America (Jaksic \& Lima, 2003), or to adjust the thresholds for conducting control.

384 Interactions between mice and their competitors or predators are captured implicitly in the model via the

385 density-independent and density-dependent growth rates. However, making these interactions explicit

386 by including rate of change of equations for other interacting species in the system, could offer additional

387 insights, e.g. into cascading responses across different trophic levels. For instance, an equation for stoat

388 density could be included in the model to consider the effectiveness of targeting mice as vectors for

389 secondary poisoning of stoats. In addition, this work could be extended to relate the mouse densities

390 expected under different control regimes to outcomes for indigenous biota, as this will be another key

391 factor for determining the optimal approach and assessing whether conservation objectives are being

392 met.

393 In this work, we have attempted to maintain approximately equal costs across each control scenario by

394 comparing regimes with similar long-term frequency (e.g. annual vs. biennual-biannual). We assume that

395 low, moderate and high effort poisoning will likely have similar overall costs since the operational costs

396 (e.g. aerial transport and/or application, labour costs) are relatively large and constant compared to

397 equipment costs (e.g. traps, bait). However, a cost-benefit analysis of higher and lower frequency control 398 regimes could also be undertaken. 
399 Our results assume the same distribution of summer temperatures over a 1000 year time-series; however

400 the effects of climate change could be investigated by relaxing this assumption. If consumer-resource

401 dynamics are altered due to climate change, our model could be useful for guiding how management

402 timing and intensity should be modified to still be effective in reducing the mouse population. For 403 example, our model would be compatible with a recently developed framework, based on the Kelly et al. 404 (2013) model, that uses climate projections to assess whether climate change might affect the frequency 405 or spatial extent of beech forest masts (Barron et al., 2016).

406

407 Conclusions

408

410

411

412

413

414

415

416

417

418

419

420

With large-scale predator control campaigns causing pest control to ramp up across New Zealand's mainland (Russell et al., 2015), there are opportunities to answer increasingly complex questions around the impacts of broad-scale invasive pest management for ecosystems, and to determine optimal control practices. We have attempted to fill an important knowledge gap concerning broad-scale control of irrupting mouse populations in masting beech forest, however a deeper understanding of climate-driven consumer-resource dynamics and control outcomes will benefit managers globally. In a rapidly changing world, having the modelling tools in place to make good predictions about the behaviour of such systems, puts us in a stronger position to anticipate and mitigate the potential adverse effects of change.

\section{Acknowledgements}

The authors thank John Innes for helpful discussions, and Andrea Byrom and Roger Pech for useful comments on manuscript drafts. 
421 Figure Captions

422 Figure 1: Example one year (Feb-Feb) time series of mouse density (C/100TN) (A) and seedfall (seeds $\mathrm{m}^{-2}$ )

423 (B, log scale) through time, modelled using three different seedfall levels: high (a mast year, the $75^{\text {th }}$

424 percentile of the seedfall distribution, black solid line); median ( $50^{\text {th }}$ percentile of the seedfall distribution,

425 blue dashed line); low ( $25^{\text {th }}$ percentile of the seedfall distribution, green dot-dashed line). The mouse

426 plague level is defined such that, for an initial mouse density of 1 , if the seedfall is at or below the median

427 level, there is no plague (grey horizontal line, A only). Note that the start of the year coincides with the

428 start of the seedfall season. When high level control takes place at the start of the seedfall season

429 (February 1) in a mast year (black dotted line, A and B), the mouse density is much reduced compared to

430 no control in a mast year (c.f. black solid line, A) and seed remains available until the end of the year (c.f.

431 black solid line, B). With control, the seedfall is closer to the seedfall in the absence of mice (red dashed

432 line, B only).

433

434 Figure 2: A 20 year example time series for mouse density $(A)$ and seedfall (B, log scale) in the absence of 435 control. The dashed lines show the defined plague level for the mouse population and the seedfall mast 436 level. The plague threshold is exceeded in $85 \%$ of years and for $71 \%$ of the total time.

Figure 3: The effect of timing of annual control on plague time (A) and plague size (B), for low (red), medium (blue dashed) and high (green dot-dashed) control levels, and compared to no control (black 
442 throughout the year. Plague size is more strongly affected by control timing, particularly for low and 443 medium control levels.

445 Figure 4: Time series of mouse density (C/100TN) for each of the three control levels (low, medium and 446 high) applied annually (red lines), compared against mouse density with no control (black lines). The black 447 dashed line shows the mouse density plague level. A, C, E show control applied in autumn (March), B, D, 448 F show control applied in early spring (September). Low control stops plagues in only the years with the 449 lowest plague size. Contrastingly, high control reduces mouse density to below the plague threshold in 450 almost all years but in the highest plague years mouse populations still persist.

451

452 
453

454

455

456

457

458

459

460

461

462

463

464

465

466

467

468

469

470

471

472

473

474

475

476

477

478

479

480

481

482

483

484

485

486

487

488

489

490

491

492

493

494

\section{References}

Allen, R. B., Mason, N. W. H., Richardson, S. J., \& Platt, K. H. (2012). Synchronicity, periodicity and bimodality in inter-annual tree seed production along an elevation gradient. Oikos, 121(3), 367376. doi:10.1111/j.1600-0706.2011.19306.x

Barron, M. C., Pech, R. P., Christie, J. E., Tait, A., Byrom, A., \& Elliot, G. (2016). Climate change impacts and implications: an integrated assessment in the alpine case study. Synthesis report: RA2 Alpine Case Study. The beech forests of New Zealand. Climate Change Impacts and Implications for New Zealand to 2100. MBIE contract C01X1225. 19 p.

Biswas, S., Kumar, S., \& Mittal, V. (2016). A note on rodent migration following gregarious bamboo flowering in north eastern hill region with particular reference to Mizoram (India) and its consequences. Journal of Common Diseases, 48(3), 1-12.

Blackwell, G. L., Potter, M. A., \& McLennan, J. A. (2002). Rodent density indices from tracking tunnels, snap-traps and Fenn traps: do they tell the same story? New Zealand Journal of Ecology, 26(1), 43-51.

Broome, K., Golding, C., Brown, K., Horn, S., Corson, P., \& Bell, P. (2017). Mouse eradication using aerial baiting: Current agreed best practice used in New Zealand (Version 1.0). New Zealand Department of Conservation. Wellington, New Zealand.

Choquenot, D., \& Ruscoe, W. A. (2000). Mouse population eruptions in New Zealand forests: the role of population density and seedfall. Journal of Animal Ecology, 69, 1058-1070.

Crooks, K. R., \& Soulé, M. E. (1999). Mesopredator release and avifaunal extinctions in a fragmented system. Nature, 400, 563. doi:10.1038/23028

Deter, J., Chaval, Y., Galan, M., Gauffre, B., Morand, S., Henttonen, H., Laakkonen, J., Voutilainen, L., Charbonnel, N., \& Cosson, J.-F. (2008). Kinship, dispersal and hantavirus transmission in bank and common voles. Archives of Virology, 153(3), 435-444.

Eason, C. T., Murphy, E. C., Wright, G. R. G., \& Spurr, E. B. (2002). Assessment of risks of brodifacoum to non-target birds and mammals in New Zealand. Ecotoxicology, 11, 35-48.

Elliott, G., \& Kemp, J. (2016). Large-scale pest control in New Zealand beech forests. Ecological Management \& Restoration, 17(3), 200-209. doi:10.1111/emr.12227

Fisher, P., \& Airey, A. T. (2009). Factors affecting 1080 pellet bait acceptance by house mice (Mus musculus). DOC Research and Development Series 306. New Zealand Department of Conservation. Wellington, New Zealand.

Fitzgerald, B. M., Daniel, M. J., Fitzgerald, A. E., Karl, B. J., Meads, M. J., \& Notman, P. R. (1996). Factors affecting the numbers of house mice (Mus musculus) in hard beech (Nothofagus truncata) forest. Journal of the Royal Society of New Zealand, 26(2), 237-249.

Holland, E. P., \& James, A. (2015). Assessing the efficacy of population-level models of mast seeding. Theoretical Ecology, 8(1), 121-132. doi:10.1007/s12080-014-0238-4

Holland, E. P., James, A., Ruscoe, W. A., Pech, R. P., \& Byrom, A. E. (2015). Climate-based models for pulsed resources improve predictability of consumer population dynamics: outbreaks of house mice in forest ecosystems. PLoS One, 10(3), e0119139. doi:10.1371/journal.pone.0119139

Innes, J., Kelly, D., McC. Overton, J., \& Gillies, C. (2010). Predation and other factors currently limiting New Zealand forest birds. New Zealand Journal of Ecology, 34(1), 86-114. 
495

496

497

498

499

500

501

502

503

504

505

506

507

508

509

510

511

512

513

514

515

516

517

518

519

520

521

522

523

524

525

526

527

528

529

530

531

532

533

534

535

536

537

538

539
Innes, J., Warburton, B., Williams, D., Speed, H., \& Bradfield, P. (1995). Large-scale poisoning of ship rats (Rattus rattus) in indigenous forests of the North Island, New Zealand. New Zealand Journal of Ecology, 19(1), 5-17.

Jaksic, F. M., \& Lima, M. (2003). Myths and facts on ratadas: Bamboo blooms, rainfall peaks and rodent outbreaks in South America. Austral Ecology, 28, 237-251.

Janzen, D. H. (1971). Seed predation by animals. Annual Review of Ecology and Systematics, 2, 465-492.

Jedrzejewska, B., \& Jedrzejewski, W. (1998). Predation in Vertebrate Communities. The Bialowieza Primeval Forest as a Case Study. Ecological Studies, 135, 230-231. Springer-Verlag Berlin Heidelberg.

Jones, C., \& Toft, R. (2006). Impacts of mice and hedgehogs on native forest invertebrates: a pilot study. DOC Research and Development Series 245. New Zealand Department of Conservation. Wellington, New Zealand.

Jones, C. G., Ostfeld, R. S., Richard, M. P., Schauber, E. M., \& Wolff, J. O. (1998). Chain reactions linking acorns to gypsy moth outbreaks and Lyme disease risk. Science, 279(5353), 1023-1026.

Kelly, D., Geldenhuis, A., James, A., Penelope Holland, E., Plank, M. J., Brockie, R. E., Cowan, P. E., Harper, G. A., Lee, W. G., Maitland, M. J., Mark, A. F., Mills, J. A., Wilson, P. R., \& Byrom, A. E. (2013). Of mast and mean: differential-temperature cue makes mast seeding insensitive to climate change. Ecol Lett, 16(1), 90-98. doi:10.1111/ele.12020

Kelly, D., \& Sork, V. L. (2002). Mast Seeding in Perennial Plants: Why, How, Where? Annual Review of Ecology and Systematics, 33(1), 427-447. doi:10.1146/annurev.ecolsys.33.020602.095433

King, C. M. (1983). The relationships between beech (Nothofagus sp.) seedfall and populations of mice (Mus musculus), and the demographic and dietary responses of stoats (Mustela erminea), in three New Zealand forests. Journal of Animal Ecology, 52(1), 141-166.

Mackay, J. W. B., Russell, J. C., \& Murphy, E. C. (2007). Eradicating house mice from islands: successes, failures and the way forward. Paper presented at the Managing vertebrate invasive species: proceedings of an international symposium, Fort Collins, USDA/APHIS/WS, National Wildlife Research Centre.

Magarey, R. D., \& Isard, S. A. (2017). A troubleshooting guide for mechanistic plant pest forecast models. Journal of Integrated Pest Management, 8(1).

Miller, C. J., \& Miller, T. K. (1995). Population dynamics and diet of rodents on Rangitoto Island, New Zealand, including the effect of a 1080 poison operation. New Zealand Journal of Ecology, 19, 19-27.

Murphy, E., Gillies, C., Maddigana, F., McMurtrie, P., Edge, K.-A., Rohan, M., \& Clapperton, K. (2016). Flexibility of diet of stoats on Fiordland islands, New Zealand. New Zealand Journal of Ecology, 40(1). doi:10.20417/nzjecol.40.13

Murphy, E. C., Robbins, L., Young, J. B., \& Dowding, J. E. (1999). Secondary poisoning of stoats after an aerial 1080 poison operation in Pureora Forest, New Zealand. New Zealand Journal of Ecology, 23(2), 175-182.

Mutze, G., \& Sinclair, R. (2004). Efficacy of zinc phosphide, strychnine and chlorpyrifos as rodenticides for the control of house mice in South Australian cereal crops. Wildlife Research, 31, 249-257.

Newsome, A. E. (1969). A population study of house-mice temporarily inhabiting a South Australian wheatfield. Journal of Animal Ecology, 38, 341-359.

Norbury, G., Byrom, A., Pech, R., Smith, J., Clarke, D., Anderson, D., \& Forrester, G. (2013). Invasive mammals and habitat modification interact to generate unforeseen outcomes for indigenous fauna. Ecological Applications, 23(7), 1707-1721. 
540

541

542

543

544

545

546

547

548

549

550

551

552

553

554

555

556

557

558

559

560

561

562

563

564

565

566

567

568

569

570

571

572

573

574

575

576

577

578

579

580

581

582

583

584

585

Norbury, G., van den Munckhof, M., Neitzel, S., Hutcheon, A., Reardon, J., \& Ludwig, K. (2014). Impacts of invasive house mice on post-release survival of translocated lizards. New Zealand Journal of Ecology, 38(2), 322-327.

O'Connor, C. E., Morriss, G., \& Murphy, E. C. (2005). Toxic bait avoidance by mice. Paper presented at the Proceedings of the 13th Australasian Vertebrate Pest Conference, Wellington, New Zealand.

O'Donnell, C. F. J., \& Phillipson, S. M. (1996). Predicting the incidence of mohua predation from the seedfall, mouse, and predator fluctuations in beech forests. New Zealand Journal of Zoology, 23, 287-293.

Ostfeld, R. S., \& Keesing, F. (2000). Pulsed resources and community dynamics of consumers in terrestrial ecosystems. TREE, 15(6), 232-237.

Pearse, I. S., Koenig, W. D., \& Knops, J. M. H. (2014). Cues versus proximate drivers: testing the mechanism behind masting behaviour. Oikos, 123, 179-184.

Pucek, Z., Jedrzejewski, W., Jedzrejewski, B., \& Pucek, M. (1993). Rodent population dynamics in a primeval deciduous forest (Biolowieza National Park) in relation to weather, seed crop and predation. Acta Theriologica, 38(2), 199-232.

Ritchie, E. G., \& Johnson, C. N. (2009). Predator interactions, mesopredator release and biodiversity conservation. Ecology Letters, 12, 982-998.

Ruscoe, W. A. (1996). Spatial variability in population levels of Rattus sordidus in north Queensland cane growing districts: ecological and gene flow hypotheses (PhD Thesis). Queensland University of Technology, Brisbane, Australia.

Ruscoe, W. A. (2001). Advances in New Zealand mammalogy 1990-2000: House mouse. Journal of the Royal Society of New Zealand, 31(1), 127-134.

Ruscoe, W. A., Choquenot, D., Heyward, R., Yockney, I., Young, N., \& Drew, K. (2003) Seed production, predators and house mouse population eruptions in New Zealand beech forests. ACIAR Monograph No. 96. Rats, mice and people: rodent biology and management (pp. 334-337).

Ruscoe, W. A., Goldsmith, R., \& Choquenot, D. (2001). A comparison of population estimates and abundance indices for house mice inhabiting beech forests in New Zealand. Wildlife Research, 28, 173-178.

Ruscoe, W. A., \& Murphy, E. C. (2005). House Mouse. In: C. M. King (Ed.), The handbook of New Zealand mammals (pp. 203-221). Melbourne, Australia: Oxford University Press.

Ruscoe, W. A., \& Pech, R. P. (2010). Rodent outbreaks in New Zealand. In: G. Singleton, S. Belmain, P. Brown, \& B. Hardy (Eds.), Rodent outbreaks: ecology and impacts (pp. 239-251). Manila, Phillipines, International Rice Research Institute.

Ruscoe, W. A., Wilson, D., McElrea, L., McElrea, G., \& Richardson, S. J. (2004). A house mouse (Mus musculus) population eruption in response to rimu (Dacrydium cupressinum) seedfall in southern New Zealand. New Zealand Journal of Ecology, 28(2), 259-265.

Russell, J. C., Innes, J. G., Brown, P. H., \& Byrom, A. E. (2015). Predator-free New Zealand: conservation country. Bioscience, 65(5), 520-525.

Simberloff, D. (2002) Today Tiritiri Matangi, tomorrow the world!: are we aiming too low in invasives control? Turning the tide: the eradication of invasive species. (pp. 4-12). IUCN, Gland, Switzerland and Cambridge, UK. IUCN SSC Invasive Species Specialist Group.

Singleton, G., Belmain, S., Brown, P., \& Hardy, B. (2010). Rodent outbreaks: ecology and impacts (G. Singleton, S. Belmain, P. Brown, \& B. Hardy Eds.): International Rice Research Institute.

Singleton, G., Krebs, C. J., Davis, S., Chambers, L., \& Brown, P. (2001). Reproductive changes in fluctuating house mouse populations in southeastern Australia. Proceedings of the Royal Society of London. Series B: Biological Sciences, 268(1477), 1741-1748. doi:10.1098/rspb.2001.1638 
586

Singleton, G. R., Tann, C. R., \& Krebs, C. J. (2007). Landscape ecology of house mouse outbreaks in southeastern Australia. Journal of Applied Ecology, 44, 644-652.

Smith, H., Dickman, C., \& Banks, P. (2016). Nest predation by commensal rodents in urban bushland remnants. PLoS One, 11(6), e0156180.

Smith, M. C., Gomulkiewicz, R., \& Mack, R. N. (2015). Potential role of masting by introduced bamboos in deer mice (Peromyscus manuculatus) population irruptions holds public health consequences. PLoS One, 10(6).

Studholme, B. (2000). Ship rat (Rattus rattus) irruptions in South Island beech (Nothofagus) forest. Conservation Advisory Science Notes: 318. New Zealand Department of Conservation. Wellington, New Zealand.

Turchin, P., \& Ostfeld, R. S. (1997). Effects of density and season on the population rate of change in the meadow vole. Oikos, 78(2), 355-361.

Wardle, J. A. (1984). The New Zealand beeches: ecology, utilitization and management. New Zealand Forest Service. Wellington, New Zealand.

Watts, C., Innes, J., Wilson, D., Fitzgerald, N., Bartlam, S., Thornburrow, D., \& Smale, M. (2017). Impacts of mice alone on biodiversity: final report of a Waikato field trial. Landcare Research contract report LC2747.

Wilson, D. J., McElrea, G. J., McElrea, L. M., Heyward, R. O., Peach, R. M. E., \& Thompson, C. (2006). Potential conservation impacts of high-altitude small mammals: a field study and literature review. DOC Research and Development Series 248. New Zealand Department of Conservation. Wellington, New Zealand.

Wilson, P. R., Karl, B. J., Toft, R. J., Beggs, J. R., \& Taylor, R. H. (1998). The role of introduced predators and competitors in the decline of kaka (Nestor meridionalis) populations in New Zealand. Biological Conservation, 83(2), 175-185. 


\section{Table $\mathbf{1}$ (on next page)}

Parameters and variables 
Table 1. Parameters and variables

\begin{tabular}{|c|c|c|c|}
\hline Parameters & Symbol & Value & Units \\
\hline Demographic efficiency & $\alpha$ & 1 & mice (seeds $\left.\mathrm{m}^{-2}\right)^{-1}$ \\
\hline Density independent birth & $\mu_{1}$ & -1.23 & year $^{-1}$ \\
\hline Density dependent mortality & $\mu_{2}$ & 0.76 & mouse $^{-1}$ year $^{-1}$ \\
\hline Maximum per capita feeding rate & C & 6.74 & seeds $\mathrm{m}^{-2}$ mouse $^{-1}$ year $^{-1}$ \\
\hline Foraging efficiency & $e$ & 1.08 & $\left(\text { seeds } \mathrm{m}^{-2}\right)^{-1}$ \\
\hline Seedfall decay & $\bar{h}$ & 9.48 & year $^{-1}$ \\
\hline Bait decay & $d$ & 50 & year $^{-1}$ \\
\hline Control level & $B_{0}$ & $50,100,150$ & -- \\
\hline \multicolumn{4}{|l|}{ Variables } \\
\hline Mouse density & $M(t)$ & -- & $\begin{array}{l}\text { mice (measured as an index }=\text { captures } \\
\text { per } 100 \text { trap nights }(\mathrm{C} / 100 \mathrm{TN}))\end{array}$ \\
\hline Available resource density & $\mathrm{F}(\mathrm{t})$ & -- & seeds $\mathrm{m}^{-2}$ \\
\hline Resource delivery rate & $S(t)$ & -- & seeds $\mathrm{m}^{-2}$ year $^{-1}$ \\
\hline Mortality rate due to control & $B(t)$ & -- & year $^{-1}$ \\
\hline
\end{tabular}

2 


\section{Table 2 (on next page)}

Effectiveness of control regimes.

Plague time, proportion of time density is above the plague level. Plague years, proportion of years maximum density exceeds the plague level. Plague size (C/100TN) maximum density during plague years. All values calculated from 1000 year time series. Control is carried out in mid-September for annual control or two weeks either side for regular biennial control. For each control level, the minimum expected plague time, plague years and plague size across the different regimes are shown in bold text. 
1 Table 2. Effectiveness of control regimes. Plague time, proportion of time density is above the plague

2 level. Plague years, proportion of years maximum density exceeds the plague level. Plague size (C/100TN)

3 maximum density during plague years. All values calculated from 1000 year time series. Control is carried

4 out in mid-September for annual control or two weeks either side for regular biennial control. For each

5 control level, the minimum expected plague time, plague years and plague size across the different

6 regimes are shown in bold text.

\begin{tabular}{|c|c|c|c|c|c|c|c|c|c|}
\hline & \multicolumn{3}{|c|}{ Plague time } & \multicolumn{3}{|c|}{ Plague years } & \multicolumn{3}{|c|}{ Plague size (C/100TN) } \\
\hline Level & Low & Med & High & Low & Med & High & Low & Med & High \\
\hline None & \multicolumn{3}{|c|}{0.72} & \multicolumn{3}{|c|}{0.85} & \multicolumn{3}{|c|}{5.78} \\
\hline Annual & 0.35 & 0.20 & 0.042 & 0.56 & 0.43 & 0.15 & 6.39 & 5.53 & 4.39 \\
\hline \multicolumn{10}{|l|}{ Biannual } \\
\hline Regular biennial & 0.42 & 0.23 & 0.056 & 0.62 & 0.45 & 0.16 & 5.96 & 5.48 & 4.73 \\
\hline Seedfall driven & 0.34 & 0.18 & 0.048 & 0.55 & 0.41 & 0.15 & 6.43 & 5.96 & 5.16 \\
\hline Climate driven & 0.39 & 0.20 & 0.057 & 0.57 & 0.41 & 0.13 & 6.27 & 5.93 & 5.41 \\
\hline
\end{tabular}

7 


\section{Figure 1}

Example one year (Feb-Feb) time series of mouse density and seedfall

Example one year (Feb-Feb) time series of mouse density (C/100TN) (A) and seedfall (seeds $\left.\mathrm{m}^{-2}\right)(B, \log$ scale) through time, modelled using three different seedfall levels: high (a mast year, the $75^{\text {th }}$ percentile of the seedfall distribution, black solid line); median ( $50^{\text {th }}$ percentile of the seedfall distribution, blue dashed line); low ( $25^{\text {th }}$ percentile of the seedfall distribution, green dot-dashed line). The mouse plague level is defined such that, for an initial mouse density of 1 , if the seedfall is at or below the median level, there is no plague (grey horizontal line, A only). Note that the start of the year coincides with the start of the seedfall season. When high level control takes place at the start of the seedfall season (February 1) in a mast year (black dotted line, A and B), the mouse density is much reduced compared to no control in a mast year (c.f. black solid line, A) and seed remains available until the end of the year (c.f. black solid line, B). With control, the seedfall is closer to the seedfall in the absence of mice (red dashed line, B only). 

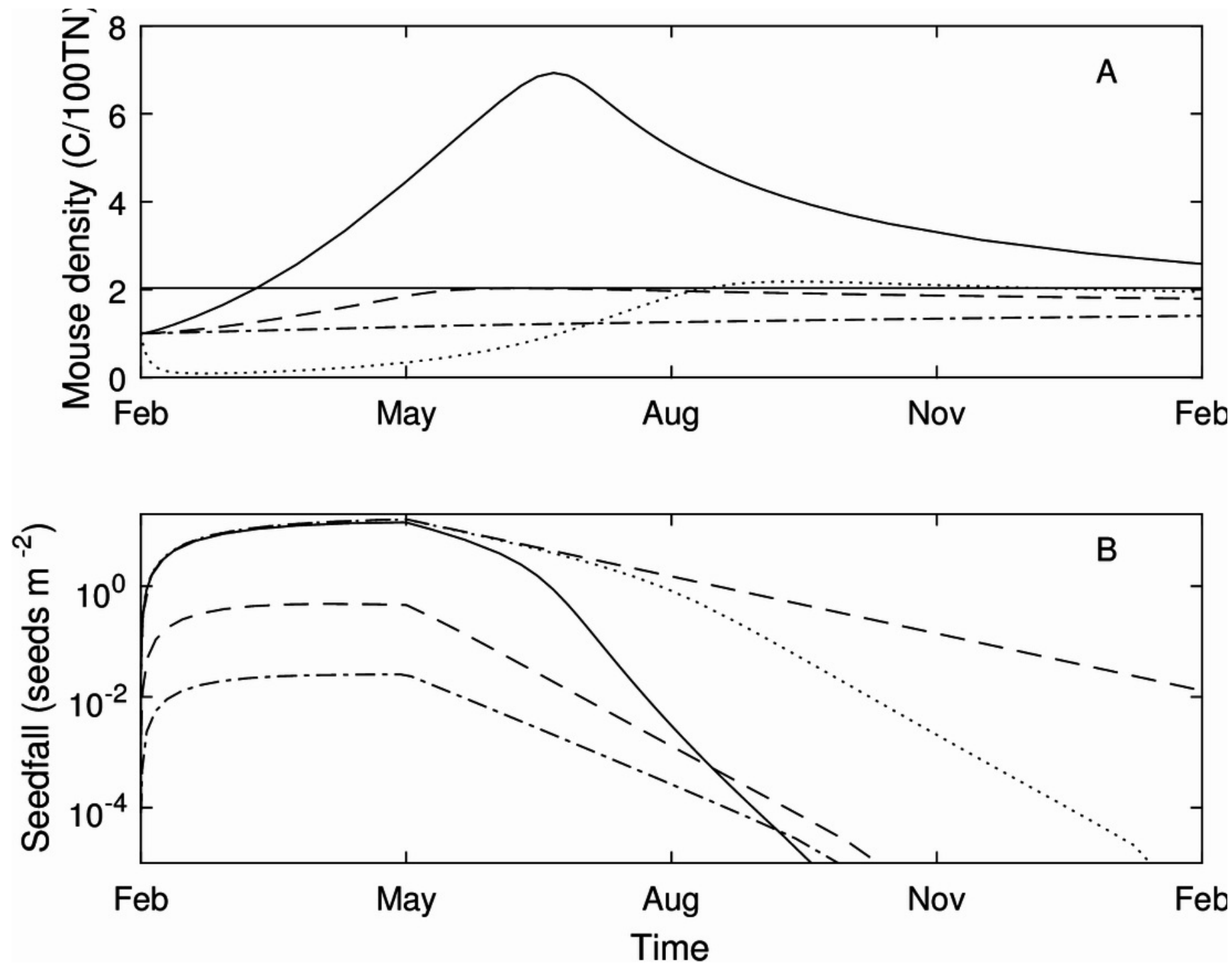
Figure 2

A 20 year example time series for mouse density and seedfall in the absence of control

A 20 year example time series for mouse density $(A)$ and seedfall (B, log scale) in the absence of control. The dashed lines show the defined plague level for the mouse population and the seedfall mast level. The plague threshold is exceeded in $85 \%$ of years and for $71 \%$ of the total time.
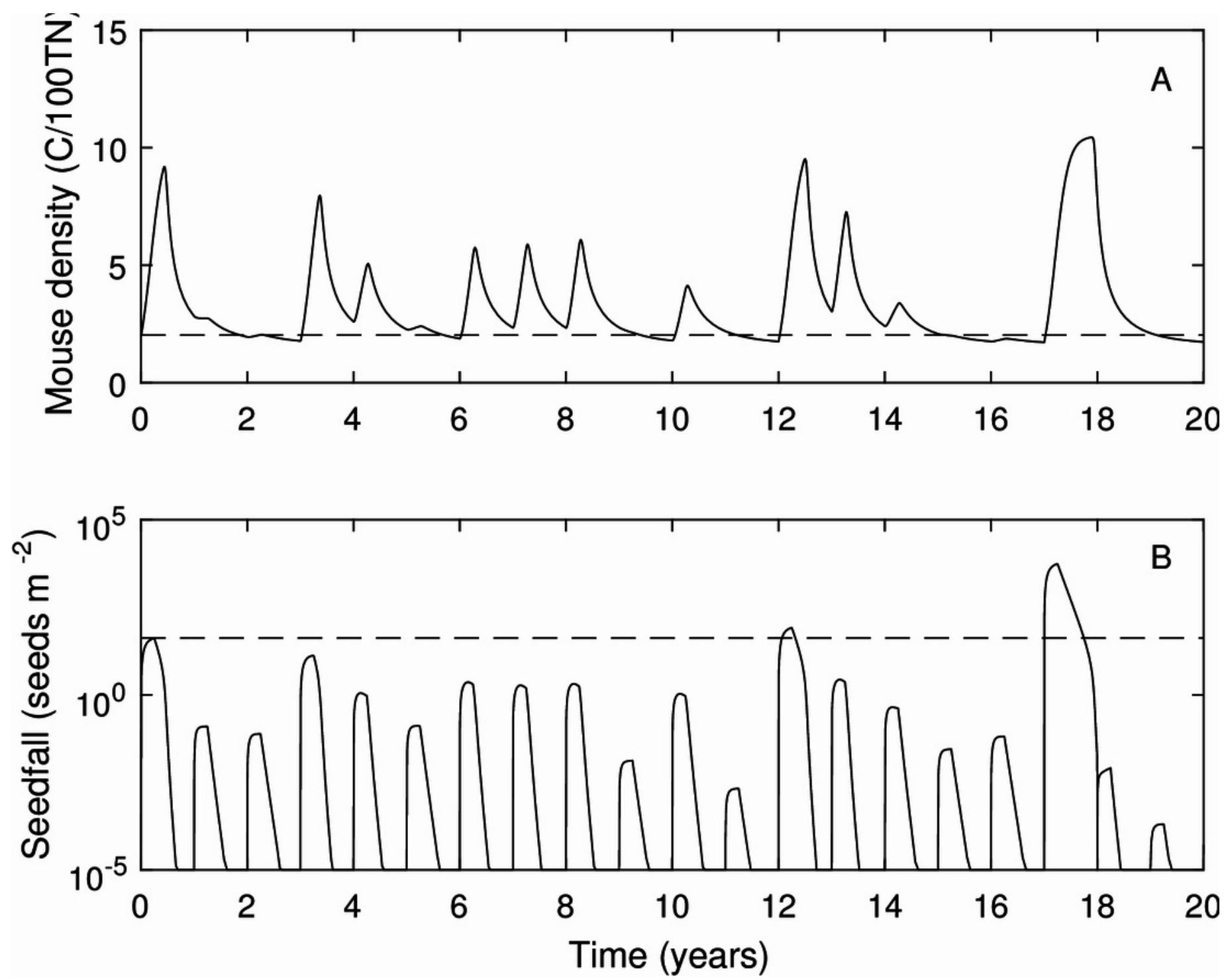


\section{Figure 3}

The effect of timing of annual control on plague time and plague size

The effect of timing of annual control on plague time (A) and plague size (B), for low (red), medium (blue dashed) and high (green dot-dashed) control levels, and compared to no control (black dashed). If control has a low success rate then optimal control timing is midSeptember. However, if control is more effective then there is little difference in plague time if control is applied at different times throughout the year. Plague size is more strongly affected by control timing, particularly for low and medium control levels.
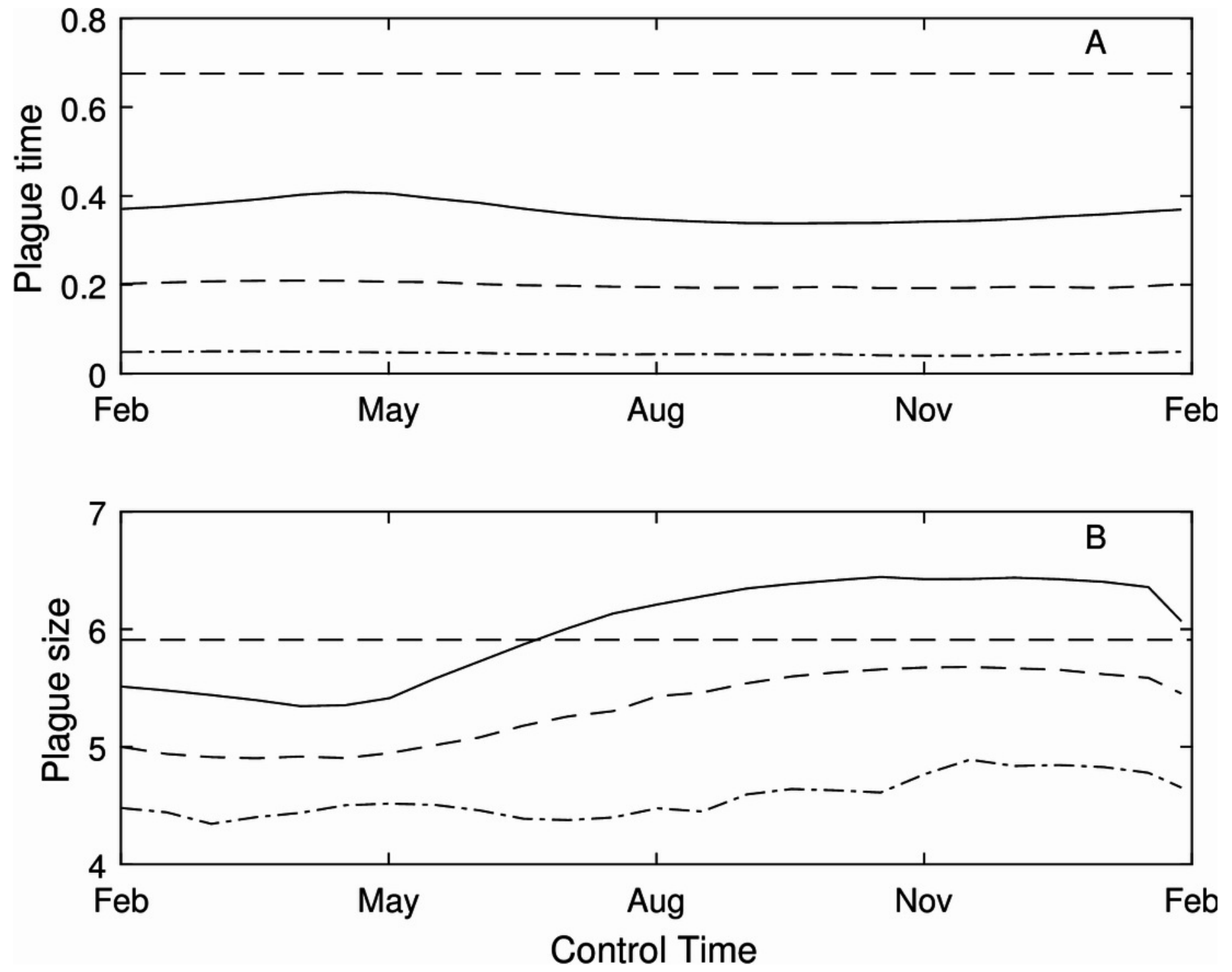


\section{Figure 4}

Time series of mouse density for each of the three control levels applied annually, compared against mouse density with no control

Time series of mouse density (C/100TN) for each of the three control levels (low, medium and high) applied annually (red lines), compared against mouse density with no control (black lines). The black dashed line shows the mouse density plague level. A, C, E show control applied in autumn (March), B, D, F show control applied in early spring (September). Low control stops plagues in only the years with the lowest plague size. Contrastingly, high control reduces mouse density to below the plague threshold in almost all years but in the highest plague years mouse populations still persist. 

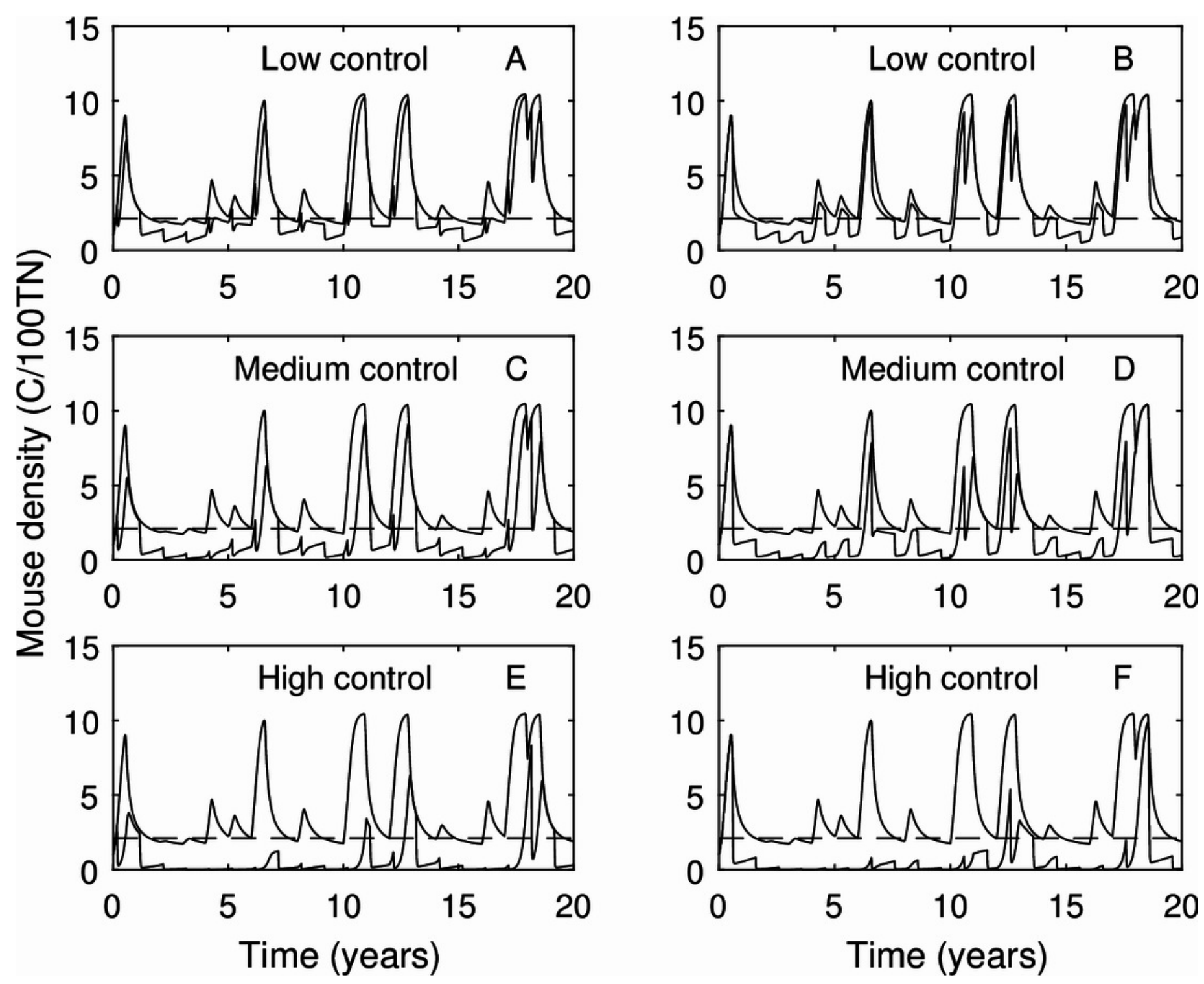